\title{
Relations Between Positive Impacts Of CSR, External Support, CSR Knowledge And The Degree Of CSR Practices In Thai Small And Medium Enterprises
}

Pornpimon Eua-anant, Khon Kaen University, Thailand

Dusadee Ayuwat, Khon Kaen University, Thailand

Buapun Promphakping, Khon Kaen University, Thailand

\begin{abstract}
This article investigates the relations between positive impacts from Corporate Social Responsibility (CSR), external support, knowledge about CSR and the degree of CSR practices according to international standards in the viewpoint of small and medium enterprises in Thailand. The survey among 262 small and medium enterprises in five sections in the northeastern region of Thailand reveals that positive impacts of CSR on internal issues have shown to be positively related to the degree of CSR practices in small and medium enterprises. While there is no clear evidence supporting the positive impacts of CSR on external issues, external support and knowledge of owners/managers of small and medium enterprises about CSR have influenced the degree of CSR practices. The results indicate that, for CSR practices according to international standards, Thai small and medium enterprises are more interested in internal issues providing tangible benefits for them. In addition, external support for Thai small and medium enterprises in CSR engagement may not be enough to have a noticeable effect on the degree of CSR practices in Thai small and medium enterprises.
\end{abstract}

Keywords: Corporate Social Responsibility; Small and Medium Enterprises

\section{INTRODUCTION}

$\mathrm{n}$ the era of globalization, corporate social responsibility (CSR) is a new trend in which many businesses are interested and that is widely practiced to create benefits for society and the environment and, in return, receive social appreciation and an increase in the sustainability of their business. Started in western countries, CSR has gradually emerged from large multinational enterprises that have plenty of resources. Later on, government agencies and private companies have joined together to standardize and promote CSR. Today, as CSR becomes a global phenomenon, CSR has seeped into all levels of government and private sectors from large state enterprises to small, privately owned enterprises, both in developed and developing countries. International standards related to CSR, such as ISO26000, are becoming widely recognized issues. Nevertheless, several researches have revealed that CSR aspects vary, place by place, country by country, depending on several factors, such as government policies, socio-economic priorities, and economic, political and social conditions (e.g., Baughn, Bodie, \& Mcintoch, 2007; Visser, 2008; Welford, 2005). For example, businesses in developed countries gave CSR priority to legal responsibility before philanthropic responsibility, while businesses in developing countries gave CSR priority to philanthropic responsibility before legal responsibility (Visser, 2008), while Baughn et al. (2007) found a strong relationship between CSR and a country's economic, political and social contexts. Most early researchers and practitioners had focused on CSR in large scale enterprises where CSR practices had been adopted conspicuously and well publicized (e.g., Aupperle, Carroll, \& Hatfield, 1985; Aupperle, Hatfield, \& Carroll, 1983; Pinkston \& Carroll, 1994). Nevertheless, recognition of the importance of small and medium enterprises (SMEs) representing the majority of businesses and the growing impacts of SMEs on economics has led to an emphasis on CSR research in SMEs. 


\section{CSR in Thailand}

In Southeast Asia, Thailand is one of the leading countries engaging in the CSR agenda. Although, compared to CSR activities in developed countries, CSR activities in Thailand have emerged only recently, within a decade, Thailand's leading companies have quickly caught up with the CSR agenda. Welford (2005) reported that the CSR activities of Thailand's leading companies were relatively prominent in external issues, especially community engagement, ethics and child labor but placed less emphasis on internal issues such as employees compared to other Asian countries. This finding is consistent with the paper by Chapple and Moon (2005) indicating that, in Thailand, as well as India and Malaysia, there was a greater emphasis on community involvement than production processes. The paper by Kraisornsuthasinee and Swierczek (2006) revealed that community engagement initiatives played a vital role in CSR in Thailand's leading companies, while philanthropic activities were given much less emphasis. Nevertheless, for Thai SMEs, the CSR agenda seems to be quiet and neglected even though there were 2,827,633 SMEs in 2008, accounting for $99.7 \%$ of all enterprises in Thailand and about 37.8 percent of Thailand GDP (The Office of Small and Medium Enterprises Promotion of Thailand, 2009). Thai SMEs play a key role in Thailand's economic progress and recovery. Promoting CSR in Thai SMEs will improve the social performance of businesses and create benefits for wider society. Therefore, in order to develop a CSR framework for Thai SMEs, this paper has focused on CSR in Thai SMEs, especially, the factors related to the degree of CSR practices in Thai SMEs according to international standards from their own perspective.

\section{LITERATURE REVIEW}

Although Corporate Social Responsibility (CSR) has no precise definition, as a broad concept, CSR is the way companies manage their business processes to produce an overall positive impact on society (Baker, 2010). The essential characteristic of CSR is the willingness of an organization to incorporate social and environmental considerations into its decision making and be accountable for the impacts of its decisions and activities on society and the environment (ISO, 2010). By international standards, CSR covers topics including philanthropic activities, labor practices, fair operating practices, human rights, the environment, consumer protection and countering fraud and corruption.

\section{Characteristics of CSR in SMEs: Informal, Limited Patterns, and Obstacles}

During two decades, much CSR research has paid attention to CSR in SMEs in comparison with CSR in large enterprises and have reported that CSR in SMEs differs from that in large enterprises in various aspects such as patterns, practices, strategies, tools, influential factors, issues and obstacles (e.g., Castka, Balzarova, Bamber, \& Sharp, 2004; Jenkins, 2006; Morsing \& Perrini, 2009; Russo \& Tencati, 2009; Spence \& Lozano, 2000; Vyakarnam, Bailey, Myers, \& Burnett,1997). Much research suggested that CSR in SMEs tended to be informal rather than the formal CSR usually found in large firms (e.g., Fassin, 2008; Graafland, Ven, \& Stoffele, 2003; Spence \& Lozano, 2000) and depended mainly on the attitudes or values of the owners or managers (e.g., Murillo \& Lozano, 2006; Spence \& Lozano, 2000). In addition, cultural background, beliefs, religion, family and friends of the enterprise owners affect CSR (e.g., Nejati \& Amram, 2009; Spence \& Lozano, 2000; Xu \& Yang, 2010). For CSR strategies, SMEs usually use an informal CSR strategy with the expectation that business will survive in society while large enterprises usually do not include a CSR strategy into their business strategies. Traditional CSR tools such as code of conducts, reports and monitoring, standards and certifications used in large firms seem to be less effective and hence less utilized in SMEs (Graafland et al., 2003; Spence \& Lozano, 2000) and may even create difficulties for SMEs instead of benefits (Fassin, 2008). In contrast, SMEs prefer to use informal tools such as personal ties that support SMEs owners in dealing with ethical issues (Graafland et al., 2003). SMEs also prefer to learn through networking and from their peers (Jenkins, 2006). For CSR issues, while large firms usually focus on the environment, employment, communities and reports and monitoring, SMEs are more concerned with issues related to their own supply chain such as customers and social demand, since CSR practices focusing on employees and customers have concrete positive impacts on the firm and its business performance (Hamman, 2009). Since SMEs must depend on interpersonal relationships and relations with communities in doing business, SMEs prefer to invest in social capital by means of CSR. Some CSR issues found in large enterprises are also not recognized by SMEs (Lepoutre \& Heene, 2006). Compared to large enterprises, SMEs usually encounter more obstacles in CSR engagement, especially the lack of financial resources, labor, knowledge, skills (Avram \& Kühne, 2008; Lepoutre \& 
Heene, 2006), and managerial tools (Russo \& Tencati, 2009).

\section{CSR Motivations}

Various factors influencing businesses in adopting CSR in their business practices have been listed including the benefits of CSR, external support, regulations, market orientation, social demand, the environment, culture, and ethics and attitudes of owners/managers (e.g., Jenkins, 2006; Murrilo \& Lozano, 2006; Qu, 2007; Wang \& Juslin, 2009; Williamson, Lynch-Wood, \& Ramsay, 2006; Visser, 2008). Maignan and Ralston (2002) categorized motivations of CSR into three perspectives: utilitarian, compliance and commitment. In the utilitarian perspective, business benefits obtained from CSR are the main motivations for businesses to engage in CSR practices. In the compliance perspective, external pressure such as government regulation, social demand, and pressure from supply chain and stakeholders, as seen in the work by Luken and Stares (2005), drives businesses to behave appropriately in order to conform to norms and social expectations. Sometimes, factors from different perspectives affect the same CSR issues. For example, Williamson et al. (2006) considered business performance, a factor in the utilitarian perspective, and regulation, a factor in the compliance perspective, as drivers of the environmental behavior of SMEs.

In the commitment perspective, businesses may be self-motivated to adopt CSR regardless of social pressures. Although there are many reasons for SMEs to be interested in CSR, in this perspective, the most influential factor for SMEs to engage in CSR is the ethical and moral attitudes of the owners/managers. Unlike large enterprises that are well organized and steered by organization boards, SMEs are usually directed solely by owner's decisions. Hence, the major motivating factor for SMEs to engage in CSR is not external pressure but an ethical reason of the owners/managers that drive SMEs to "do the right thing" (Jenkins, 2006).

\section{Positive Impacts of CSR on SMEs}

In order to survey factors in the utilitarian perspective influencing SMEs on practicing CSR, positive impacts from CSR are subjects to be examined. In this research, positive impacts of CSR are categorized into two types: impacts on internal issues and on external issues. Impacts of CSR on internal issues include creating good corporate image, decreasing problems, increasing employee's morale and productivity, stimulating and spreading innovation and helping businesses to survive in a crisis. For impacts of CSR on external issues, this research is not only interested in impacts of CSR activities by individual enterprises such as increasing market share and customer accessibility, getting loan from financial institutes easier, trading with foreign countries easier, but also the impacts of CSR by other enterprises that affect the SMEs such as the global trend toward CSR. As suggested by Maignan and Ralston (2002), in the utilitarian perspective, positive impacts of CSR should drive SMEs to participate in CSR activities. Therefore, in this paper, positive impacts of CSR are proposed as factors influencing the degree of CSR practices in SMEs to be examined under the following hypotheses in which impacts of CSR on internal and external issues are separated into 2 hypotheses in order to precisely identify the effect of each factor.

H1: The degree of CSR practices in SMEs relates to positive impacts of CSR on internal issues.

H2: The degree of CSR practices in SMEs relates to positive impacts of CSR on external issues.

\section{External Support}

External support for CSR in SMEs can come in many forms. Battaglia, Bianchi, Frey, and Iraldo (2011) proposed a cluster approach for promoting CSR in SMEs by establishing multi-stakeholder working groups while Jenkins (2006) suggested the use of CSR learning networks to promote CSR among SMEs. In this concept, social capital is strengthened by cooperation between multiple stakeholders and firms thus allowing greater access to local resources. Government can also support CSR in SMEs in many ways, as suggested by Jenkins (2006) and reported by Moon (2004), for example, by defining CSR policies, enacting laws supporting CSR activities done by SMEs, and/or establishing organizations responsible for coaching, educating, promoting and auditing CSR in SMEs. In this paper, external support is investigated under the following hypothesis:

H3: External support has an influence on the degree of CSR practices in SMEs. 


\section{Knowledge of SME Owners/manager about CSR}

Several studies on business ethics indicate that there is a positive relation between education level and individual's ethics, where individuals with a higher level of education tended to be more ethical (e.g., Giacalone, Payne, \& Rosenfeld, 1988; Kraft \& Singhapakdi,1991; Kum-Lung, 2010). Since business ethics is intimately linked to CSR, it is expected that SME owners/managers with higher education levels will tend to be more ethical and, thus, have more knowledge about CSR and be more interested in practicing CSR. In this paper, in order to screen factors related to the degree of CSR practices in SMEs, further investigation is conducted about the relationship between education level, especially in terms of SME owners'/managers' knowledge about CSR, and the degree of CSR practices in SMEs. The following hypothesis is proposed:

H4: The level of knowledge of SME owners/managers about CSR influences the degree of CSR practices in SMEs.

Figure 1 shows the conceptual model depicting the overall relationships between positive impacts of CSR, external support, CSR knowledge of SME owners/managers and the degree of CSR practices in SMEs proposed in this research.

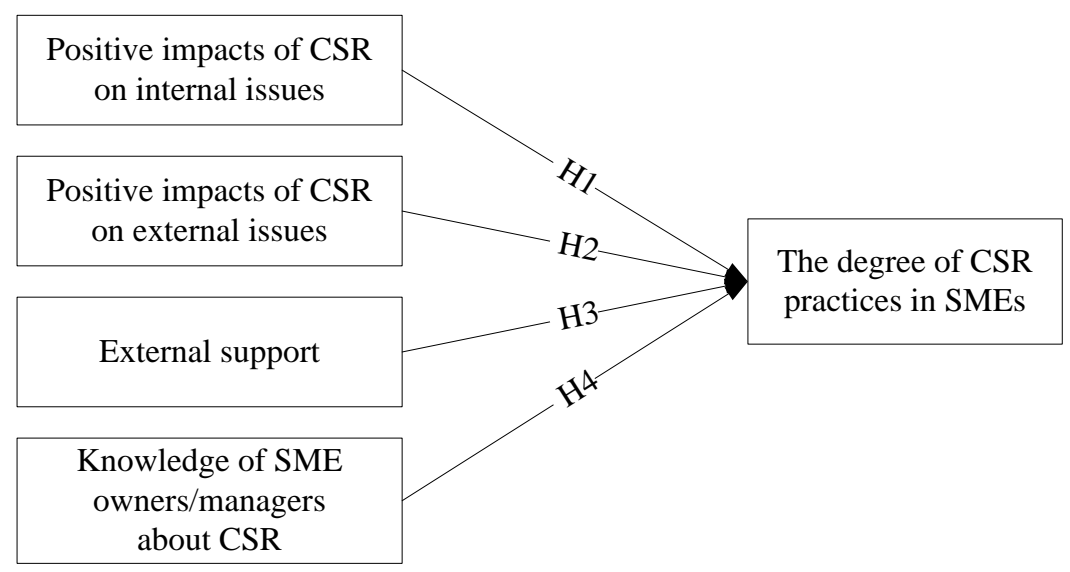

Figure 1: Hypothesized relationships between impacts of CSR, external support, knowledge of SMES about CSR and degree of CSR practices in SMEs

\section{RESEARCH METHODOLOGY}

\section{Sample and Data Collection}

This research collected empirical data using an in-depth questionnaire survey among owners/managers of SMEs in the northeastern region of Thailand. In this research, SMEs were classified by type, number of employees, and amount of capital as defined by the Small and Medium Enterprises Promotion Act of Thailand (Ministry of Industry, 2000). The questionnaire covered general information, knowledge and comprehension of the informant about CSR, the degree of CSR practices in their enterprise according to international standards, the informant's perception of the benefits of CSR and the impacts of CSR on his/her enterprise, CSR priorities that the enterprise gave to related groups, priorities of CSR issues in which the enterprise was interested and external support from government and organizations. Verification procedures including expert review, focus group critique, pre-testing, and reliability testing were performed on the questionnaire before real data collection. The SMEs sample group consisted of SMEs in five sections in 18 provinces in the northeastern region of Thailand. Among 360 questionnaires given directly or mailed to owners/managers of SMEs, there were a total of 262 questionnaires returned as shown in Table 1. 
Table 1: The Sample Group For Quantitative Analysis

\begin{tabular}{|l|c|c|c|}
\hline \multirow{2}{*}{ Business Section } & Small No. of Enterprises & \multirow{2}{*}{ Total } \\
\cline { 2 - 4 } & 55 & 60 & 115 \\
\hline Manufacturing & 25 & 8 & 33 \\
\hline Services & 58 & 24 & 82 \\
\hline Wholesale & 3 & 8 & 11 \\
\hline Retail & 13 & 8 & 21 \\
\hline Maintenance & 154 & 108 & 262 \\
\hline Total & & & \\
\hline
\end{tabular}

\section{Measurement}

Ten specific yes-or-no questions about CSR were used to measure the informant's knowledge about and comprehension of CSR. Positive impacts of CSR, external support and the degree of CSR practices in SMEs, listed in Appendix, were measured using a 4-point rating scale from "very low" (1) to "very high" (4). The informants were asked to answer the questions according to their perceptions. For CSR practices, CSR topics were classified into six categories as follows: organizational governance, human rights and labor practices, the environment, fair operating practices, consumer issues and Community involvement, and development similar to international standard ISO 26000 except that, in this research, human right and labor practices were grouped into the same topic. The degree of CSR practices in each topic is an average value of scores obtained from questions in that topic. Table 2 shows the mean and standard deviation (SD) of each measurable variable while the average knowledge score obtained from the survey is 5.31 from a full scale of 10 with $\mathrm{SD}=2.06$.

Table 2: Mean, SD and Cronbach's $\alpha$ of Measureable Variables

\begin{tabular}{|c|c|c|c|}
\hline Items & $\begin{array}{c}\text { Mean } \\
(1=\text { Very low, } 4=\text { Very high })\end{array}$ & SD & Cronbach's $\alpha$ \\
\hline Degree of CSR practices 1 & 2.67 & 0.53 & \multirow{6}{*}{0.88} \\
\hline Degree of CSR practices 2 & 2.93 & 0.49 & \\
\hline Degree of CSR practices 3 & 3.06 & 0.46 & \\
\hline Degree of CSR practices 4 & 3.00 & 0.50 & \\
\hline Degree of CSR practices 5 & 2.86 & 0.50 & \\
\hline Degree of CSR practices 6 & 2.81 & 0.58 & \\
\hline Positive impacts of CSR on internal issues 1 & 3.05 & 0.52 & \multirow{5}{*}{0.84} \\
\hline Positive impacts of CSR on internal issues 2 & 2.92 & 0.58 & \\
\hline Positive impacts of CSR on internal issues 3 & 2.84 & 0.62 & \\
\hline Positive impacts of CSR on internal issues 4 & 2.98 & 0.60 & \\
\hline Positive impacts of CSR on internal issues 5 & 2.87 & 0.63 & \\
\hline Positive impacts of CSR on external issues 1 & 2.56 & 0.86 & \multirow{5}{*}{0.80} \\
\hline Positive impacts of CSR on external issues 2 & 2.76 & 0.65 & \\
\hline Positive impacts of CSR on external issues 3 & 2.89 & 0.65 & \\
\hline Positive impacts of CSR on external issues 4 & 2.54 & 0.74 & \\
\hline Positive impacts of CSR on external issues 5 & 2.81 & 0.64 & \\
\hline External support 1 & 2.36 & 0.82 & \multirow{6}{*}{0.96} \\
\hline External support 2 & 2.47 & 0.85 & \\
\hline External support 3 & 2.20 & 0.88 & \\
\hline External support 4 & 2.31 & 0.84 & \\
\hline External support 5 & 2.28 & 0.84 & \\
\hline External support 6 & 2.31 & 0.83 & \\
\hline
\end{tabular}

\section{ANALYSIS AND RESULTS}

First, data obtained from the questionnaires was tested for scale reliability (Cronbach's $\alpha=0.85$ ) followed by exploratory factor analysis using principal component analysis (Kaiser-Meyer-Olkin Measure of Sampling Adequacy $=0.88$ ). The results from principal component analysis revealed that there were five components with eigenvalues greater than 1.0 which suggested that measurable variables should be grouped into five groups: positive impacts of CSR on internal issues, positive impacts of CSR on external issues, external support, Knowledge of SME 
owners/managers about CSR, and the degree of CSR practices in Thai SMEs. According to the result in Table 2, all Cronbach's $\alpha$ values, between 0.80 and 0.96 , are above the value recommended $(0.70)$ by Nunnally and Bernstein (1994).

Next, to investigate the relations between the degree of CSR practices and other variables, structural equation modeling analysis was performed using LISREL 8.72 similar to the method used by Lai, Chiu, Yang, and Pai (2010) and Qu (2007). The advantage of SEM analysis is that the method can simultaneously assess relationships between each independent variable and the dependent measure (Joreskog \& Sorbom, 1993). After several model adjustments, the results revealed that $\chi^{2}=106.98(\mathrm{p}=1.00) ; d f=156 ; \chi^{2} / d f=0.69$ (recommended value $<2.0$ ); RMSEA $=0.0$ (recommended value $<0.05$ ); GFI $=0.96$, AGFI $=0.92$, NFI $=0.98$, $\mathrm{NNFI}=1.01, \mathrm{CFI}=1.00($ Recommended values $>0.9) ; \mathrm{CN}=382.30($ Recommended value $>200) ; \mathrm{NCP}=0.0$ (Recommended value near 0.0); and standardized RMR $=0.042$ (Recommended value $<0.05$ ) in which all of the parameters in goodness of fit statistics were better than the recommended values (Bollen, 1989; Diamantopoulos \& Siguaw, 2000). Consequently, the goodness of fit between the model and the observed data in this research should be acceptable.

The SEM analysis results are provided in Table 3 and the corresponding structural model is shown in Figure 2. According to the results, only positive impacts of CSR on internal issues $\left(\gamma_{11}=0.51, t=4.88\right)$ are obviously shown to have a positive influence on the degree of CSR practices in SMEs $\left(R^{2}=0.36\right)$. On the other hand, the test statistic $t$ values of the relations of positive impacts of CSR on external issues, external support, and knowledge of SME owners/managers about CSR to the degree of CSR practices in Thai SMEs do not reach a critical $t$ value (1.96) for a significance level of 0.05 . Hence, there is no clear evidence from SEM analysis that these three factors: positive impacts of CSR on external issues, external support and knowledge of SME owners/managers about CSR have any influence on the degree of CSR practices in Thai SMEs. In addition, factor loading values of these factors are very small compared to that of positive impacts of CSR on internal issues. Consequently, only H1 is supported by this finding.

Table 3: Standardized Coefficients of The Obtained Structural Model, ${ }^{* *}$ Sig. $=0.01$

\begin{tabular}{|l|c|c|}
\hline \multicolumn{1}{|c|}{ Independent Variables } & Factor Loading $(\gamma)$ & $t$ \\
\hline Positive impacts of CSR on internal issues & $0.51^{* *}$ & 4.88 \\
\hline Positive impacts of CSR on external issues & 0.08 & 0.88 \\
\hline External support & 0.08 & 1.29 \\
\hline Knowledge of SME owners/managers about CSR & -0.11 & -1.70 \\
\hline
\end{tabular}

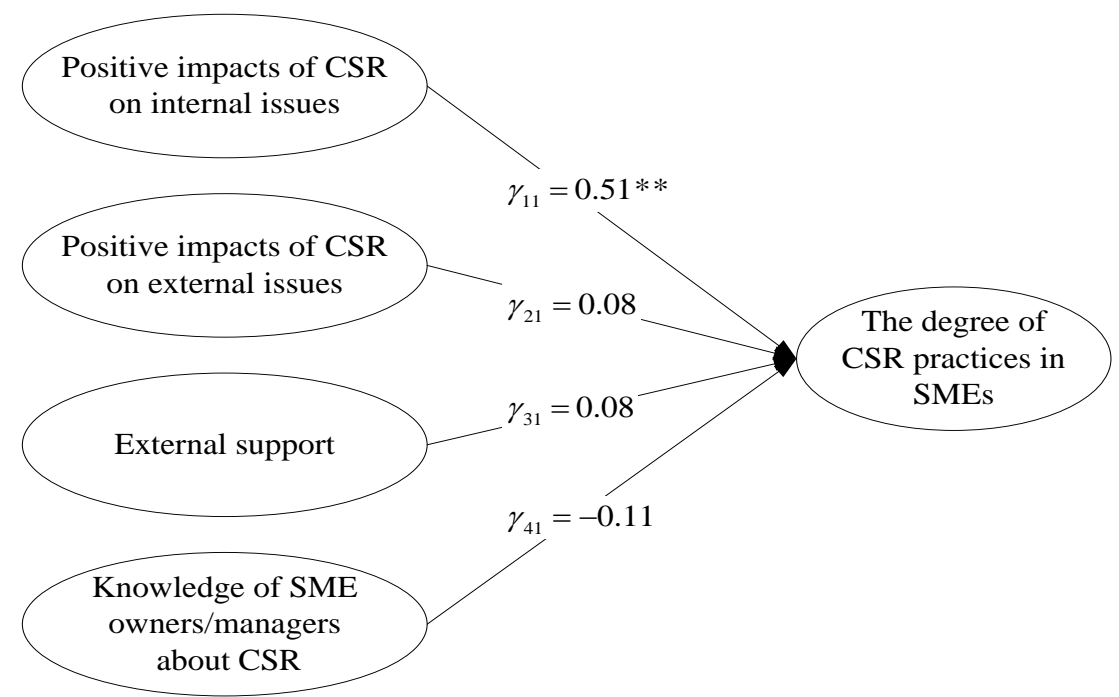

Figure 2: The Obtained Structural Model of Relation Between Positive Impacts of CSR, External Support, Knowledge of SME Owners/Managers about CSR and the Degree of CSR Practices in Thai Smes, ${ }^{* *}$ Sig. $=0.01$. 


\section{DISCUSSIONS}

The obtained results suggest that, for CSR practices according to international standards, Thai SMEs are more interested in positive impacts of CSR on internal issues which are mostly tangible and affect their business performance. This finding is consistent with earlier papers suggesting that SMEs were more interested in issues related to their survivability or supply chain and preferred tangible benefits (Hamman, 2009; Perrini, Russo, \& Tencati, 2007; Russo \& Tencati, 2009). In addition, this finding disagrees with the findings in previous CSR research in Thailand's large enterprises which stated that Thailand's leading companies placed more emphasis on community engagement (Chapple \& Moon, 2005; Kraisornsuthasinee \& Swierczek, 2006; Welford, 2005). For positive impacts of CSR on external issues, no relationship to the degree of CSR practices in SMEs is found. This may be explained by the fact that positive impacts of CSR on external issues such as increasing market share and customer accessibility, ease in trading with foreign countries, or getting loan from financial institutes more easily are difficult to be measured or likely intangible. In other words, positive impacts of CSR on external issues are likely unobservable. It may not be worthwhile for SMEs to invest in CSR in order to achieve such impacts.

For external support, this research does not find evidence that supports a relationship to the degree of CSR practices in Thai SMEs. This may result from a lack of external support as can be seen from the results in Table 2 where average scores of external support items are classified as "low" $(<2.5)$ compared to those of positive impacts of CSR which are rated "High" $(>2.5)$. So in the Thai SME perspective, external support in terms of legislation, funding, educating, coaching, networking that help promote CSR in SMEs is currently inadequate.

For knowledge about the CSR of Thai SME owners/managers, an average score of 5.63 out of 10 indicates that the CSR comprehension of Thai SMEs is still poor or below expectations. In Table 3, a knowledge score seems to be less negatively correlated to the degree of CSR practices in SMEs. Surprisingly, the obtained results somewhat contrast with the findings in previous business ethics research where individuals with higher education levels tended to be more ethical (Giacalone et al., 1988; Kraft \& Singhapakdi,1991; Kum-Lung, 2010). However, in this previous research, overall education levels of respondents were examined but, in this research, the narrow scope of knowledge in CSR issues is being tested instead. The results indicate that, despite the CSR knowledge they have, some SMEs may know CSR well but may not practice CSR or Thai SMEs may not pay enough attention to acquire knowledge about CSR. In other words, the knowledge of SME owners/managers is not shown to be an influencing factor that drives SME to engage in CSR practices. On the other hand, in SME's mind, attitude, ethics and social value of SME owners/managers, play key roles in driving CSR activities in SMEs instead (Jenkins, 2006; Murillo \& Lozano, 2006).

\section{CONCLUSIONS}

The findings in this research reveal one important notion that the degree of CSR practices, according to international standards, in Thai SMEs is positively related to positive impacts of CSR on internal issues. In other words, in the utilitarian perspective, Thai SMEs are more interested in positive impacts of CSR on internal issues when they engage in an international style CSR agenda where CSR practices can return foreseeable concrete benefits to the businesses. On the other hand, no evidence is found in this research that confirms the relations between positive impacts of CSR on external issues, as well as external support and knowledge of SME owners/managers about CSR, and the degree of CSR practices in Thai SMEs. The study also reveals the present deficiency of external support for Thai SMEs to engage in CSR practices.

\section{AUTHOR INFORMATION}

Pornpimon Eua-anant is currently a PhD student in the development science program, Faculty of Humanities and Social Sciences, Khon Kaen University, Khon Kaen, Thailand. She received a Master Degree from the National Institute of Development Administration, Bangkok, Thailand in 1998. Her current research focuses on corporate social responsibility. Email: pornpims@scg.co.th

Dusadee Ayuwat is currently working at the faculty of Humanities and Social Sciences, Khon Kaen University, Khon Kaen, Thailand. She finished her doctoral degree in Demography from Institute for Population and Social 
Research (IPSR), Mahidol University Bangkok, Thailand in 1997. Most of her researches focus on demographic issues and organization capability such as migration and well-being, international labor, human security and community development capability. Email: dusayu@kku.ac.th

Buapun Promphakping is currently working at the faculty of Humanities and Social Sciences, Khon Kaen University, Khon Kaen, Thailand. He finished his doctoral degree in Development Study from Bath University, UK. He is expert in social development. Email: buapun@kku.ac.th

\section{REFERENCES}

1. Aupperle, K. E., Carroll, A. B., \& Hatfield, J. D. (1985). An Empirical Examination of the Relationship between Corporate Social Responsibility and Profitability. Academy of Management Journal, 28(2), 446463.

2. Aupperle, K. E., Hatfield, J. D., \& Carroll, A. B. (1983). Instrument Development and Application in Corporate Social Responsibility. Academy of Management Proceedings, 369-373.

3. Avram, D.O., \& Kühne, S. (2008). Implementing Responsible Business Behavior from a Strategic Management Perspective: Developing a Framework for Austrian SMEs. Journal of Business Ethics, 82, 463-475.

4. Baker, M. (2010). Corporate Social Responsibility -What does it mean? Retrieved from http://www.mallenbaker.net/csr/definition.php

5. Battaglia, M., Bianchi, L., Frey, M., \& Iraldo, F. (2010). An Innovative Model to Promote CSR among SMEs Operating in Industrial Clusters: Evidence from an EU Project. Corporate Social Responsibility and Environmental Management, 17, 133-141.

6. Baughn, C. C., Bodie, N. L., \& Mcintoch, J. C. (2007). Corporate Social and Environmental Responsibility in Asian Countries and Other Geographical Regions. Corporate Social Responsibility and Environmental Management, 14, 189-205.

7. $\quad$ Bollen, K. A. (1989). Structural Equations with Latent Variables, New York: Wiley.

8. Brammer, S., Williams, G., \& Zinkin, J. (2007). Religion and Attitudes to Corporate Social Responsibility in a Large Cross-Country Sample. Journal of Business Ethics, 71, 229-243.

9. Castka, P., Balzarova, M.A., Bamber, C. J., \& Sharp, J.M. (2004). How can SMEs effectively implement the CSR agenda? A UK Case Study Perspective. Corporate Social Responsibility and Environmental Management, 11, 140-149.

10. Chapple, W. \& Moon, J. (2005). Corporate social responsibility (CSR) in Asia: a seven-country study of CSR web site reporting. Business and Society, 44(4), 415-441.

11. Diamantopoulos, A. \& Siguaw, A. D. (2000). Introducing LISREL: A guide for the uninitiated, Sage Publications, London.

12. Fassin, Y. (2008). SMEs and the fallacy of formalising CSR. Business Ethics: A European Review, 17, 364-378.

13. Giacalone, R., Payne, S.L., \& Rosenfeld, P. (1988). Endorsement of managers following accusations of breaches in confidentiality. Journal of Business Ethics, 7, 621-629.

14. Graafland, J., Ven, B., \& Stoffele, N. (2003). Strategies and Instruments for Organising CSR by Small and Large Businesses in the Netherlands. Journal of Business Ethics, 47(1), 45-60.

15. Hammann, E., Habisch, A., \& Pechlaner, H. (2009). Values that create value: socially responsible business practices in SMEs - empirical evidence from German companies. Business Ethics: A European Review, 18(3), 37-51.

16. International Organization for Standardization (2010). ISO/FDIS 26000:2010(E) Guidance on Social Responsibility, Geneva.

17. Jenkins, H. (2006). Small Business Champions for Corporate Social Responsibility. Journal of Business Ethics, 67, 241-256.

18. Joreskog, K., \& Sorbom, D. (1993). LISREL8: Structural Equation Modeling With the Simplis Command Language, Chicago: Scientific Software International.

19. Kraft, K.L., \& Singhapakdi, A. (1991). The role of ethics and social responsibility in achieving organizational effectiveness: Students versus managers. Journal of Business Ethics, 10, 679-686. 
20. Kraisornsuthasinee, S., \& Swierczek, F. (2006). Interpretations of CSR in Thai Companies. Journal of Corporate Citizenship, 22, 53-65.

21. Kum-Lung, C. (2010). Attitude towards Business Ethics: Examining the Influence of Religiosity, Gender and Education Levels. International Journal of Marketing Studies, 2(1), 225-232.

22. Lai, C., Chiu, C., Yang, C., \& Pai, D. (2010). The Effects of Corporate Social Responsibility on Brand Performance: The Mediating Effect of Industrial Brand Equity and Corporate Reputation. Journal of Business Ethics, 95, 457-469.

23. Lepoutre, J., \& Heene, A. (2006). Investigating the Impact of Firm Size on Small Business Social Responsibility: A Critical Review. Journal of Business Ethics, 67, 257-273.

24. Luken, R., \& Stares, R. (2005). Small Business Responsibility in Developing Countries: A Threat or an Opportunity? Business Strategy and the Environment, 14, 38-53.

25. Maignan, I., \& Ralston, D. A. (2002). Corporate Social Responsibility in Europe and the US: Insights from Businesses' Self-presentations. Journal of International Business Studies, 33(3), 497-514.

26. Ministry of Industry, (2000). The Small and Medium Enterprises Promotion Act of Thailand, Thailand.

27. Moon, J. (2004). Government as a Driver of Corporate Social Responsibility. ICCSR Research Paper Series No. 20-2004, International Centre for Corporate Social Responsibility, Nottingham University Business School, Nottingham.

28. Morsing, M. \& Perrinin, F. (2009). CSR in SMEs: do SMEs matter for the CSR agenda? Business Ethics: A European Review, 18(1), 1-6.

29. Murillo, D., \& Lozano, J. (2006). SMEs and CSR: An Approach to CSR in their Own Words. Journal of Business Ethics, 67, 227-240.

30. Nunnally, J. C. \& Bernstein, I. H. (1994). Psychometric Theory, 3rd Edition (McGraw-Hill, New York).

31. The Office of Small and Medium Enterprises Promotion, (2009). Operating Result 2009, Thailand.

32. Perrini, F., Russo, A., \& Tencati, A. (2007). CSR Strategies of SMEs and Large Firms: Evidence from Italy. Journal of Business Ethics, 74, 285-300.

33. Pinkston, T. S., \& Carroll, A. B. (1994). Corporate Citizenship Perspectives and Foreign Direct Investment in the US. Journal of Business Ethics, 13(3), 157-169.

34. Qu, R. (2007). Corporate social responsibility in China: Impact of regulations, market orientation and ownership structure. Chinese Management Studies, 1(3), 198-207.

35. Russo, A., \& Tencati, A. (2009). Formal vs. Informal CSR Strategies: Evidence from Italian Micro, Small, Medium-sized, and Large Firms. Journal of Business Ethics, 85, 339-353.

36. Spence, L. J., \& Lozano, J. (2000). Communicating about ethics with small firms: Experiences from the U.K. and Spain. Journal of Business Ethics, 27(1/2), 43-53.

37. Visser, W. (2008). Corporate social responsibility in developing countries. The Oxford Handbook of Corporate Social Responsibility, 473-499.

38. Vyakarnam, S., Bailey, A., Myers, A., \& Burnett, D. (1997). Towards an understanding of ethical behaviour in small firms. Journal of Business Ethics, 16(15), 1625-1636.

39. Wang, L. \& Juslin, H. (2009). The Impact of Chinese Culture on Corporate Social Responsibility: The Harmony Approach. Journal of Business Ethics, 88, 433-451.

40. Welford, R. (2005). Corporate Social Responsibility in Europe, North America and Asia: 2004 Survey Results. Journal of Corporate Citizenship, 17(1), 33-52.

41. Williamson, D., Lynch-Wood, G., \& Ramsay, J. (2006). Drivers of Environmental Behaviour in Manufacturing SMEs and the Implications for CSR. Journal of Business Ethics, 67, 317-330. 


\section{APPENDIX}

\section{Impacts of CSR on Internal Issues}

1. CSR creates good corporate image for our enterprise.

2. CSR reduces problems in our enterprise.

3. CSR helps our enterprise to survive in a crisis.

4. CSR increases our employees' morale and productivity.

5. CSR stimulates and spreads innovation in our enterprise.

\section{Impacts of CSR on External Issues}

1. CSR helps our enterprise trade with foreign countries more easily.

2. Rapid expansion of information technology causes our enterprise to be concerned about CSR.

3. CSR increases market share and customer accessibility of our enterprise.

4. CSR helps our enterprise to secure loans from financial institutes more easily.

5. Many enterprises are interested in and aware of business ethics and CSR, so does our enterprise.

\section{External Support}

1. Our government issues laws and regulations that support CSR.

2. Our enterprise receives help from external organizations in the form of CSR education and seminars.

3. To adopt CSR practices, our enterprise receives fund from external organizations.

4. Our enterprise has been advised by external organizations in adopting CSR practices.

5. $\quad$ Our enterprise receives support for building CSR networks.

6. External organizations help our enterprise by distributing CSR research to our enterprise.

\section{CSR Practices}

1. Organizational governance

2. Human rights and labor practices

3. Environment

4. Fair operating practices

5. Consumer issues

6. Community involvement and development 